\title{
Preoperative assessment of ovarian tumors using a modified multivariate index assay
}

\author{
Hero A. Abdurrahman ${ }^{1}$, Ariana Kh. Jawad ${ }^{2^{*}}$ (D) and Shahla K. Alalalf ${ }^{3}$
}

\begin{abstract}
Background: Preoperative differentiation between benign and malignant masses can be challenging. The aim of this research was to evaluate the performance of a modified multivariate index assay (MIA) in detecting ovarian cancer and to compare the effectiveness of gynecologist assessment, cancer antigen (CA) 125, and MIA for identifying ovarian masses with high suspicion of malignancy.

Results: This prospective observational study included 150 women with ovarian masses who underwent surgery in the Maternity Teaching Hospital from December 2014 to May 2016. Preoperative estimation of modified MIA, assessment by a gynecologist, and CA 125 level correlated with the surgical histopathology. A modified MIA was implemented because of lack of access to the software typically used. Among 150 enrolled women there were 30 cases of malignancy, including 8 cases (26\%) of early-stage ovarian cancer and 22 cases (74\%) of late-stage cancer. MIA showed high specificity (96.7\%) in detecting cancer and a sensitivity of $70 \%$, with a positive predictive value of $84 \%$ and a negative predictive value of $92.8 \%$. No significant differences were detected between the MIA results and the histopathology results $(P=0.267)$. For early-stage ovarian cancer, the sensitivity of MIA was $100 \%$ compared with 75\% for CA 125 alone.

Conclusion: MIA seems to be effective for evaluation of ovarian tumors with higher specificity and positive predictive value than CA 125 while maintaining high negative predictive value and with only a slightly lower overall sensitivity. For evaluation of early-stage ovarian cancer, MIA showed a much higher sensitivity that markedly outperformed CA 125 alone. This modified MIA strategy may be particularly useful in low resource setting.
\end{abstract}

Keywords: Multivariate index assay, CA 125, Ovarian, Tumor, Physician's assessment

\section{Background}

Ovarian cancer is the leading cause of mortality among all gynecologic cancers and the seventh most common cancer in females worldwide [1]. Approximately $10 \%$ of women will have some form of surgery for an ovarian mass during their lifetime, and although $20 \%$ of borderline ovarian tumors appear as simple cysts on ultrasound many of these tumors may proceed to malignancy later on [2]. Women with ovarian malignancies that are managed by specialized care provided by a gynecologic oncologist or in a specialized hospital have an improved mean survival time, making early diagnosis and rapid management of ovarian malignancy of paramount importance [3]. Radiologic and serum markers are relatively insensitive and as a result preoperative differentiation

\footnotetext{
* Correspondence: aryianadr@yahoo.com

${ }^{2}$ Kurdistan Board for Medical Specialists, Kurdistan, Erbil, Iraq

Full list of author information is available at the end of the article
}

between benign and malignant ovarian masses is problematic, especially in the differentiation of stage I epithelial ovarian cancer. No single ultrasound finding can differentiate between benign and malignant ovarian masses [2, 4].

Estimation of the risk of malignancy is essential when assessing ovarian masses, and the risk for malignancy has been assessed using 80 different models, including the Royal College of Obstetrician and Gynecologists guidelines. Simple models use discrete cutoff values, such as cancer antigen (CA) 125, pulsatility index, and resistive index $[2,5]$. The American College of Obstetricians and Gynecologists and the Society of Obstetricians and Gynecologists of Canada have defined guidelines for the management of premenopausal women with a pelvic mass. These guidelines consider the following features suspicious for ovarian malignancy and warranting referral to a gynecological oncologist: serum CA $125>200$ units $/ \mathrm{ml}$, ascites, evidence of abdominal 
or distant metastasis, or a first-degree relative with ovarian or breast cancer $[5,6]$. However, even in the presence of an ultrasonographically defined mass, serum CA 125 cannot reliably distinguish between a malignant or benign mass [7]. Furthermore, despite efforts to define factors that identify risk of malignancy a previous report showed that $30 \%$ of premenopausal women with ovarian cancer would not have been regarded as high risk using these guidelines [6].

As early-stage ovarian cancer carries a much more favorable prognosis than late-stage ovarian cancer there is an urgent need to identify subclinical disease. Serological markers are theoretically an ideal approach, but none of the available markers have $100 \%$ specificity and sensitivity [6]. The multivariate index assay (MIA) for ovarian cancer is composed of CA 125, beta 2-microglobulin, apolipoprotein A1 (ApoA1), transferrin, and prealbumin. These biomarkers are not used for screening but for evaluating women with a pelvic mass and can significantly improve the predictability of ovarian cancer so that patients can be referred to a subspecialist with expertise in managing ovarian cancer, thus improving clinical outcome [7]. A previous study showed that the MIA demonstrated higher sensitivity and lower specificity in detecting ovarian malignancies compared with physician assessment and CA 125 [8]. Another report showed that MIA demonstrated higher sensitivity and negative predictive value for ovarian malignancy compared with clinical impression and CA 125 in women with ovarian masses [7]. In our locality, gynecologists and general oncologists (there are no gynecologic oncologists in our locality) depend on clinical assessment, ultrasound, magnetic resonance imaging, and CA 125 level for evaluation of ovarian masses.

We aimed to introduce these biomarkers in our hospital but were unable to access the software needed for the MIA assay. Therefore, we conducted this study to evaluate the use of a modified MIA; specifically, we examined the application of a software-independent method using cut-off dependent risk classification to differentiate malignant from benign ovarian tumors and compared the effectiveness of this novel strategy with physician assessment and CA 125 for identification of ovarian masses with high suspicion of malignancy.

\section{Methods}

A prospective observational study was conducted on 150 women who were admitted for surgical management of ovarian masses in the Maternity Teaching Hospital, Erbil, Kurdistan, Iraq, from December 12014 to May 1 2016. The Maternity Teaching hospital is a tertiary referral hospital with 313 beds and the only public tertiary care hospital in Erbil Governorate (population of approximately 1,612,692). The hospital serves as a major referral center for other public and private hospitals within Erbil Governorate and provides emergency obstetrics and gynecology service $24 \mathrm{~h}$ a day.

The criteria for inclusion in the study were as follows: female aged 18 years or older, a documented ovarian mass with planned surgical intervention within 3 months of imaging, not referred to an oncologist, and consent to undergo phlebotomy. The exclusion criteria were as follows: age less than 18 years, pregnancy, no planned surgical intervention, declined phlebotomy, or had a malignancy diagnosed in the previous 5 years. Menopause was defined as absence of menses for at least 12 months or age $\geq 50$ years when the woman was unsure of her menses. All patients provided written informed consent. All patients were interviewed before the surgical intervention.

Preoperative venous blood $(5-7 \mathrm{ml})$ was collected from each patient and placed in BD plastic vacutainer tubes with clot activators. Samples were transferred to the laboratory and centrifuged, and serum was separated as soon as possible to prevent hemolysis. Serum samples were stored at $2-8{ }^{\circ} \mathrm{C}$ for up to 2 days or frozen at $-20{ }^{\circ} \mathrm{C}$.

The MVI assay incorporates CA 125 , beta 2 microglobulin, transferrin, transthyretin (prealbumin), and apolipoprotein A1. CA 125 was measured using the Elecsys CA 125 II tumor marker system (Fujirebio Diagnostics, Tokyo, Japan). The other four markers were measured on the Minineph system using Minineph kits (Binding Site Group, Birmingham, UK).

The OvaCalc software combines the value of each assay and uses the MVI assay algorithm to generate an ovarian risk malignancy index score that ranges from 0 to 10 . A score of $\geq 5$ in premenopausal women or a score of $\geq 4.4$ in postmenopausal women indicates a high probability of malignancy. This software was not available to us due to policy decisions of the manufacturing company. The unavailability of the OvaCalc software forced us to use a modified MIA to assess the validity of these biomarkers in combination for screening ovarian tumors for malignancy. We decided to score the results of the assay as follows: positive cases (indicating a high risk of malignancy) were defined when three out of the five markers were positive, and negative cases (low risk of malignancy) were indicated when $\leq 2$ markers were positive. In the individual assays, positive results were defined as CA 125 and beta 2 microglobulin values higher than normal ranges and apolipoprotein A1, transferrin, and prealbumin values lower than the normal ranges (Table 1).

For each patient, CA 125 was measured and analyzed as part of the MIA and alone. The CA 125 cutoff values were $>200 \mathrm{U} / \mathrm{ml}$ for premenopausal women and $>35 \mathrm{U} / \mathrm{ml}$ for postmenopausal women according to the published American College of Obstetrician and Gynecologists referral criteria [9]. 
Table 1 Laboratory ranges used for the multivariate index assay

\begin{tabular}{|c|c|c|}
\hline Biomarkers & Ranges & Classifications \\
\hline CA 125 & $\begin{array}{l}\text { Premenopausal, } \\
200 \text { IU/L } \\
\text { Postmenopausal, } \\
35 \mathrm{IU} / \mathrm{L}\end{array}$ & $\begin{array}{l}\text { Ranges above the upper } \\
\text { limit regarded positive [11] }\end{array}$ \\
\hline${ }^{\mathrm{a}} \beta-2$ microglobulin & $1.22-2.46 \mathrm{~g} / \mathrm{L}$ & $\begin{array}{l}\text { Ranges above the upper } \\
\text { limit regarded positive }\end{array}$ \\
\hline${ }^{\mathrm{a}}$ Transferrin & $2.24-4.06 \mathrm{~g} / \mathrm{L}$ & $\begin{array}{l}\text { Level below the lower } \\
\text { limit is regarded positive }\end{array}$ \\
\hline aApolipoprotein A1 & $1.24-2.02 \mathrm{~g} / \mathrm{L}$ & $\begin{array}{l}\text { Level below the lower } \\
\text { limit is regarded positive }\end{array}$ \\
\hline aprealbumin & $0.216-0.328 \mathrm{~g} / \mathrm{L}$ & $\begin{array}{l}\text { Level below the lower I } \\
\text { imit is regarded positive }\end{array}$ \\
\hline
\end{tabular}

${ }^{a}$ Ranges obtained from The Binding Site Group kits

Normal ranges for the other four biomarkers were obtained from the leaflet provided with the kits (The Binding Site Group, Birmingham, UK) (Table 1).

This modified MVI assay could be used to screen for malignancy before the operation in our low resource setting.

Before surgery, the enrolling gynecologic surgeon performed preoperative assessment by asking the gynecologists whether they considered the ovarian tumor to be malignant based on available clinical information such as physical examination of the patient, family history of malignancy, results of imaging such as ultrasound, and laboratory tests including CA 125 , but not the multivariate index assay. The answers were recorded as yes or no. Gynecologists were allowed to use any algorithm to determine their answer, but were not expected to explain how they reached their prediction. The gynecologists' opinions were recorded before surgery for all patients. During surgery, FIGO staging was used to surgically stage cases suspicious for cancer and the stage was recorded [10]. After surgery, results of histopathological examination were obtained for each patient from the histopathology department in the hospital laboratory.

\section{Statistical analysis}

Data were analyzed using the Statistical Package for Social Sciences (SPSS, version 22). Chi square test of association was used to compare between proportions. When the expected count of more than $20 \%$ of the cells in the table was less than 5 (which was attributed to small sample size in the cells of the table), Fisher's exact test was used [11]. The expected count of each cell of the table was calculated by multiplying the marginal totals and dividing this value by the grand total. McNemar test $(2 \times 2)$ was used when the results of the screening tests such as MIA or CA 125 were compared with a gold standard (the confirmatory test was the histopathological findings) of the same patient, as in Table 2.
Table 2 Assessing the accuracy of screening tests

\begin{tabular}{lllll}
\hline & & \multicolumn{2}{l}{$\begin{array}{l}\text { Histopathology results } \\
\text { (gold standard) }\end{array}$} & \\
\cline { 2 - 3 } & & Positive & Negative & \\
\hline Screening tests & Positive & TP & FP & TP + FP \\
like MIA & Negative & FN & TN & FN + TN \\
& & TP + FN & FP + TN & Grand total \\
\hline
\end{tabular}

$P$ value, determined by McNemar

$T P$ true positive, $T N$ true negative, $F P$ false positive, $F N$ false negative

$$
\begin{aligned}
\text { Sensitivity }= & \mathrm{TP} /(\mathrm{TP}+\mathrm{FN}) \times 100 ; \text { Specificity } \\
= & \mathrm{TN} /(\mathrm{FP}+\mathrm{TN}) \times 100 ; \text { Predictive value positive } \\
= & \left(\mathrm{PV}^{+}\right): \mathrm{TP} /(\mathrm{TP}+\mathrm{FP}) \\
& \times 100 ; \text { Predictive value negative }\left(\mathrm{PV}^{-}\right) \\
& : \mathrm{TN} /(\mathrm{FN}+\mathrm{TN}) \times 100 ; \text { Total agreement } \\
= & (\mathrm{TP}+\mathrm{TN}) / \text { Grand total }
\end{aligned}
$$

Microsoft Excel 2007 was used to plot the pie charts. A $p$ value $\leq 0.05$ was considered statistically significant.

\section{Results}

A total of 150 women with an ovarian mass were included in the study. The rate of malignancy was significantly higher among menopausal, grand multiparous, overweight, and obese women $(p<0.001)$ (Table 3$)$.

Nearly one-third (30\%) of the patients had serous cystadenoma, $18.7 \%$ had dermoid, and $12 \%$ had endometrioma (Table 4).

Approximately one-fourth of the cases (25.3\%) were suspected to be malignant according to the opinion of the senior gynecologists prior to the operation, whereas $20 \%$ were proven to be malignant by histopathological examination (Table 5). Based on tumor markers, 30 and $16.7 \%$ of the masses were suspected to be malignant according to CA 125 and MIA test results, respectively.

The sensitivities of CA 125, MIA, and clinical assessment were $83.3,70$, and $70 \%$, respectively (Table 6). When MIA and gynecologist assessment results were combined in parallel (if either or both of these tests was positive, the result of the test was considered positive), the sensitivity increased to $93.3 \%$ at the expense of specificity, which decreased to $82.5 \%$. In general, MIA gave relatively high sensitivity $(70 \%)$, specificity $(96.7 \%)$, positive predictive value $(84 \%)$, negative predictive value (92.8\%), and total agreement (91.3\%) compared with the other tests. There was no significant difference between MIA results and histopathology results $(p=0.267)$.

Out of the 150 cases sampled, 30 (19.9\%) were malignant ovarian masses. Surgical staging of the 30 malignant ovarian masses determined that 13\% were stage I, 13\% were stage II, $37 \%$ were stage III, and $37 \%$ were stage IV 
Table 3 Association of histopathological results with variables

\begin{tabular}{|c|c|c|c|c|c|c|c|c|}
\hline \multirow[b]{3}{*}{ Variables } & \multirow[b]{3}{*}{ Categories } & \multicolumn{4}{|c|}{ Histopathological results } & & & \multirow[b]{3}{*}{$p$} \\
\hline & & \multicolumn{2}{|c|}{ Malignant } & \multicolumn{2}{|c|}{ Benign } & \multicolumn{2}{|c|}{ Total } & \\
\hline & & $n$ & $\%$ & $n$ & $\%$ & $n$ & $\%$ & \\
\hline \multirow[t]{2}{*}{ Menopausal status } & Premenopausal & 6 & 5.4 & 106 & 94.6 & 112 & 100.0 & $<0.001$ \\
\hline & Postmenopausal & 24 & 63.2 & 14 & 36.8 & 38 & 100.0 & \\
\hline \multirow[t]{3}{*}{ Parity } & Nuliparous & 8 & 16.7 & 40 & 83.3 & 48 & 100.0 & 0.001 \\
\hline & Multiparous [1-4] & 4 & 7.4 & 50 & 92.6 & 54 & 100.0 & \\
\hline & Grandmultiparous (parity $\geq 5$ ) & 18 & 37.5 & 30 & 62.5 & 48 & 100.0 & \\
\hline \multirow[t]{2}{*}{ Family history of CA (breast, ovary, colon) } & Negative & 29 & 20.4 & 113 & 79.6 & 142 & 100.0 & $1^{*}$ \\
\hline & Positive & 1 & 12.5 & 7 & 87.5 & 8 & 100.0 & \\
\hline \multirow[t]{2}{*}{ Combined OCP } & Negative & 27 & 19.1 & 114 & 80.9 & 141 & 100.0 & $0.384^{*}$ \\
\hline & Positive & 3 & 33.3 & 6 & 66.7 & 9 & 100.0 & \\
\hline \multirow[t]{2}{*}{ Fertility drugs } & Negative & 28 & 20.0 & 112 & 80.0 & 140 & 100.0 & $1^{*}$ \\
\hline & Positive & 2 & 20.0 & 8 & 80.0 & 10 & 100.0 & \\
\hline \multirow[t]{2}{*}{ Smoking } & Negative & 29 & 20.0 & 116 & 80.0 & 145 & 100.0 & $1^{*}$ \\
\hline & Positive & 1 & 20.0 & 4 & 80.0 & 5 & 100.0 & \\
\hline \multirow[t]{2}{*}{ Breast feeding } & $<6$ months & 8 & 16.0 & 42 & 84.0 & 50 & 100.0 & 0.386 \\
\hline & $\geq 6$ months & 22 & 22.0 & 78 & 78.0 & 100 & 100.0 & \\
\hline \multirow{3}{*}{$\begin{array}{l}\mathrm{BMl} \\
\left(\mathrm{Kg} / \mathrm{m}^{2}\right)\end{array}$} & $<25$ & 0 & 0.0 & 18 & 100.0 & 18 & 100.0 & 0.048 \\
\hline & $25-29$ & 14 & 26.9 & 38 & 73.1 & 52 & 100.0 & \\
\hline & $\geq 30$ & 16 & 20.0 & 64 & 80.0 & 80 & 100.0 & \\
\hline
\end{tabular}

*By Fisher's exact test

$O C P$ oral contraceptive pill, $B M I$ body mass index, $C A$ carcinoma

(Fig. 1). The sensitivities of CA 125 and MIA in detecting stage I and stage II cancers were 75 and 100\%, respectively (Table 7). The specificities were 83.3 and $96.7 \%$, respectively. No significant difference was detected between MIA and histopathology results $(p=0.0125)$.

The sensitivities of CA 125 and MIA in detecting stage III and stage IV tumors were 86.4 and $59.1 \%$, respectively (Table 8). The specificities were 83.3 and $96.7 \%$,

Table 4 Distribution of patients by histopathological diagnosis

\begin{tabular}{lll}
\hline Histopathological diagnosis & Number & Percent \\
\hline Serous cystadenoma & 45 & 30.0 \\
Dermoid & 28 & 18.7 \\
Endometrioma & 18 & 12.0 \\
Mucinous cystadenoma & 16 & 10.7 \\
Serous cystadenocarcinoma & 14 & 9.3 \\
Endometrioid adenocarcinoma & 8 & 5.3 \\
Hemorrhagic luteal cyst & 7 & 4.7 \\
Follicular cyst & 6 & 4.0 \\
Mucinous cystadenocarcinoma & 3 & 2.0 \\
Krukenberg's tumor & 3 & 2.0 \\
Granulosa cell cancer & 2 & 1.3 \\
Total & 150 & 100.0 \\
\hline
\end{tabular}

respectively. No significant difference was detected between MIA and histopathology results $(p=0.267)$.

\section{Discussion}

Early detection of ovarian cancer is very important to improve patient survival. The major challenge is how to identify masses with risk of malignancy, particularly in premenopausal women [2].

In the current study, the rate of ovarian malignancy was significantly higher among postmenopausal than premenopausal women, which is consistent with a previous report [12]. Although our study showed that the rate of ovarian cancer was higher among grand multiparous women $(37.5 \%)$ than nulliparous women $(16.7 \%)$, parity

Table 5 Results of gynecologist assessment, CA 125, multivariate index assay, and histopathological findings in the cases $(n=150)$

\begin{tabular}{|c|c|c|c|c|}
\hline & \multicolumn{2}{|c|}{ Malignant } & \multicolumn{2}{|c|}{ Benign } \\
\hline & $n$ & $\%$ & $n$ & $\%$ \\
\hline Gynecologist's assessment & 38 & 25.3 & 112 & 74.7 \\
\hline CA 125 & 45 & 30.0 & 105 & 70.0 \\
\hline MIA & 25 & 16.7 & 125 & 83.3 \\
\hline Histopathology results & 30 & 20.0 & 120 & 80.0 \\
\hline
\end{tabular}


Table 6 Validity of the tests and clinical assessment compared with histopathological results

\begin{tabular}{lllllll}
\hline & Sensitivity \% & Specificity \% & PPV \% & NPV \% & Agreement \% & $P^{*}$ \\
\hline CA 125 & 83.3 & 83.3 & 55.6 & 95.2 & 83.3 & 0.004 \\
MIA & 70 & 96.7 & 84 & 92.8 & 91.3 & 0.267 \\
Gynecologist's assessment & 70 & 85.8 & 55.3 & 92 & 82.7 & 0.169 \\
MIA and/or Clinical & 93.3 & 82.5 & 57.1 & 98 & 84.7 & $<0.001$ \\
\hline
\end{tabular}

*By McNemar test

$C A$ cancer antigen, MIA multivariate index assay

is generally considered a well-established protective factor for ovarian cancer [13]. Bodelon et al. found that among 623 women diagnosed with invasive epithelial ovarian cancer, $102(16 \%)$ were nulliparous and 521 (84\%) were parous [14]. Tsilidis et al. found that compared with nulliparous women; parous women had a $29 \%$ lower risk of ovarian cancer with an $8 \%$ reduction in risk for each additional pregnancy [15].

The rate of malignancy was significantly higher among overweight women (BMI 25-30; 26.9\%) and obese women $(\mathrm{BMI}>30$; $20 \%)$ than among women with normal BMI (0\%). Beehler et al. found that compared with underweight or normal $(\mathrm{BMI} \leq 24.9)$ premenopausal women, obese (BMI > 30.0) premenopausal women had an approximately 2 -fold increase in the risk for malignancy. Postmenopausal women, however, did not show the same tendency, with only a small, non-significant decrease in risk among the heaviest women [16].

Our research showed no significant association between the rate of malignancy and family history of cancer $(p=1)$, oral contraceptive pill (OCP) use for more than 1 year $(p=0.384)$, fertility drugs (ovulation induction $>12$ cycles) $(p=1)$, smoking $(p=1)$, and breast feeding for more than 6 months $(p=0.386)$.

A meta-analysis by Havrilesky et al. showed an inverse association between OCP use and ovarian cancer [17]. Ovarian cancer risk was $25-28 \%$ lower in women with a

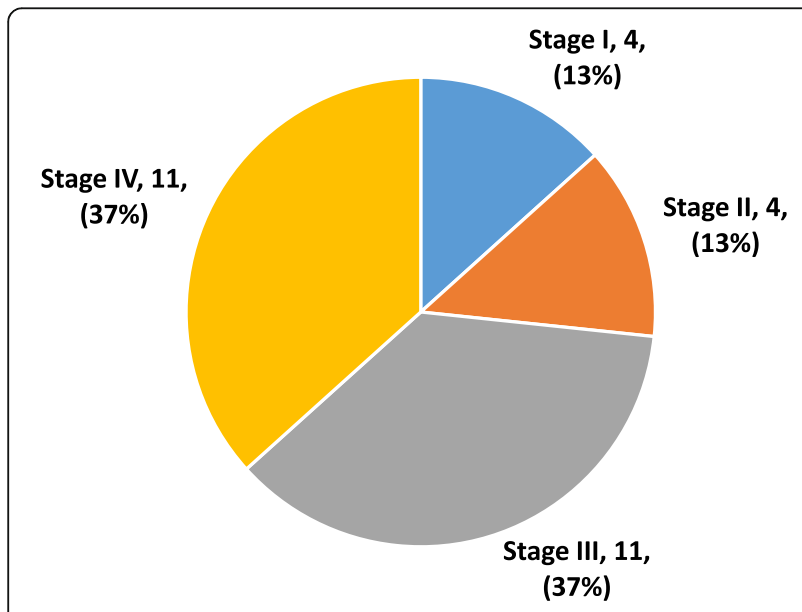

Fig. 1 Distribution of the sample by stage of the Cancer history of OCP use compared with never-users [18]. Risk was further reduced with longer duration of OCP use, and was decreased by more than $50 \%$ in women with more than 10 years of use $[19,20]$. Ovarian cancer risk in OCP ever-users remained reduced for at least 30 years after the last use of OCPs, although the protection may diminish over time [21]. The insignificant result in our study may be related to the small number of women taking OCP.

Other studies revealed marked differences in the risk profiles of various histological types of ovarian cancer with regard to cigarette smoking [21, 22]. Current cigarette smoking increased the risk of invasive mucinous and borderline mucinous ovarian tumors, whereas former smoking increased the risk of borderline serous ovarian tumors [23]. No associations between smoking and risk of invasive serous and endometrioid ovarian cancer were observed [23].

Another study reported that breastfeeding was inversely associated with the risk of ovarian cancer; in particular, long-term breastfeeding (>12 months) demonstrated a stronger protective effect [24].

Epithelial ovarian cancer has been described as a "silent killer", because advanced disease is found at initial diagnosis in more than $60 \%$ of cases. In Denmark, $74 \%$ of patients were diagnosed with FIGO stage III-IV disease, compared with $60-70 \%$ in Australia, Canada, Norway, and the UK [25]. Surgical staging of ovarian tumors operated on in a tertiary care hospital revealed that more than half $(56 \%)$ of the patients had stage III-IV disease. On histology, papillary serous cystic adenocarcinoma was found to be the most common type (54\%),

Table 7 Sensitivity of CA 125 and MIA tests in detecting stage 1 and stage 2 ovarian cancers

\begin{tabular}{|c|c|c|c|c|c|c|c|c|}
\hline & & \multicolumn{2}{|c|}{ Stage | \& || } & \multicolumn{2}{|c|}{ Benign } & \multicolumn{2}{|c|}{ Total } & \multirow[b]{2}{*}{$p$} \\
\hline & & $n$ & $\%$ & $n$ & $\%$ & $n$ & $\%$ & \\
\hline \multirow[t]{2}{*}{ CA 125} & Positive & 6 & 75.0 & 20 & 16.7 & 26 & 20.3 & $<0.001$ \\
\hline & Negative & 2 & 25.0 & 100 & 83.3 & 102 & 79.7 & \\
\hline \multirow[t]{3}{*}{ MIA } & Positive & 8 & 100.0 & 4 & 3.3 & 12 & 9.4 & 0.0125 \\
\hline & Negative & 0 & 0.0 & 116 & 96.7 & 116 & 90.6 & \\
\hline & Total & 8 & 100.0 & 120 & 100.0 & 128 & 100.0 & \\
\hline
\end{tabular}

CA 125 cancer antigen 125 , MIA multivariate index assay 
Table 8 Sensitivity of CA 125 and MIA tests in detecting stage 3 and stage 4 ovarian cancers

\begin{tabular}{|c|c|c|c|c|c|c|c|c|}
\hline & \multicolumn{2}{|c|}{ Stage III \& IV } & \multicolumn{2}{|c|}{ Benign } & \multicolumn{2}{|c|}{ Total } & \\
\hline & & $n$ & $\%$ & $n$ & $\%$ & $n$ & $\%$ & \\
\hline \multirow[t]{2}{*}{ CA 125} & Positive & 19 & 86.4 & 20 & 16.7 & 39 & 27.5 & $<0.001$ \\
\hline & Negative & 3 & 13.6 & 100 & 83.3 & 103 & 72.5 & \\
\hline \multirow[t]{3}{*}{ MIA } & Positive & 13 & 59.1 & 4 & 3.3 & 17 & 12.0 & 0.267 \\
\hline & Negative & 9 & 40.9 & 116 & 96.7 & 125 & 88.0 & \\
\hline & Total & 22 & 100.0 & 120 & 100.0 & 142 & 100.0 & \\
\hline
\end{tabular}

CA 1

followed by mucinous $22 \%$, endometrioid (10.6\%), yolk sac (2.6\%), dysgerminoma (4\%), and adult granulosa cell tumor $(5.3 \%)[26]$.

In one study, the individual accuracies of pelvic examination and serum CA 125 in discriminating between benign and malignant pelvic masses were approximately the same (76 and 77\%, respectively) [27]. A systemic review by Kristen Pepin showed that the sensitivity of CA 125 in distinguishing between benign and malignant masses ranged from 61 to $90 \%$, while the specificity ranged from 35 to $91 \%$. The positive predictive value of CA 125 in women with an adnexal mass was 35 to $91 \%$, and the negative predictive value was between 67 and 90\% [28]. Miller et al. showed that replacing CA 125 with the MIA increased the sensitivity (77-94\%) and negative predictive value (87-93\%), while decreasing specificity (35-68\%) and positive predictive value $(40-52 \%)$ [29]. Similar trends were noted for premenopausal women and those with early-stage disease.

Our modified MIA demonstrated higher sensitivity and lower specificity compared with physician assessment and CA 125 in detecting ovarian malignancies. Such a noticeable improvement in sensitivity translates into a high negative predictive value, which is a clinically important measure to assure physicians and patients that the risk of malignancy will be low for patients who have a negative result by MIA. In fact, the 92.5\% (149/161) sensitivity of MIA itself will produce a negative predictive value of 92.9\% (156/168). The addition of MIA to clinical assessment brings significant improvement in sensitivity. This is, however, at the cost of reduced specificity [7]. Longoria et al. concluded that MIA combined with clinical assessment had significantly higher sensitivity (95.3\%) compared with clinical assessment alone $(68.6 \%)$ or CA 125-II (62.8\%) [30]. In our research, MIA gave a higher specificity and negative predictive value compared with a study conducted by Bristoe et al., in which MIA demonstrated higher sensitivity and negative predictive value for ovarian malignancy compared with clinical impression and CA125-II [31].

MIA had a higher sensitivity than CA 125 in the detection of early-stage ovarian cancer (FIGO I \& II), which was consistent with the study by Ueland et al. [7]; however, this was not the case in the detection of late-stage ovarian cancers (FIGO III \& IV), for which the specificity of MIA was higher than that of CA 125 [30].

This study had several limitations. One limitation was the lack of the OvaCalc software to calculate scores; however, this is counterbalanced by the major benefit that our modified method can be used in the absence of access to software, which is the case in certain clinical settings. Another limitation is the lack of gynecologic oncology specialists in our locality.

The main strength of our study is the adaptation of available resources for discriminating ovarian tumors in a clinical setting with limited resources. Another strength of the current study lies in the inclusion of all types of ovarian malignancies that are seen in general gynecology practice. Although MIA is not intended for screening or follow-up of cases of ovarian cancer, its efficacy was proven in detecting ovarian malignancy, especially in early stages, which may significantly improve early case referral to oncology surgeons and yield a better patient survival.

\section{Conclusions}

The modified MIA applied in this study resulted in sufficient diagnostic accuracy and appears to be highly effective for the detection of ovarian malignancy. This modified MIA strategy may be a useful method for application in developing countries.

\section{Acknowledgements \\ We thank the Edanz Group (http://www.edanzediting.com/ac) for editing a draft of this manuscript.}

\section{Funding}

This work was supported by the Kurdistan Board for Medical Specializations. Financial support was for academic purposes only.

\section{Availability of data and materials}

The datasets used and/or analyzed during the current study are available from the corresponding author on reasonable request.

\section{Authors' contributions}

AKJ advised project direction and participated in manuscript writing and revision. HAA performed data collection and data analysis, and helped with manuscript revision. SKA participated in manuscript writing and revision. All authors read and approved the final manuscript.

\section{Ethics approval and consent to participate}

Approval to conduct this study was obtained from the Ethics and Scientific Committee of Kurdistan Board of Medical Specialties in November 2013. All patients provided written informed consent. Confidentiality was assured.

\section{Competing interests}

The authors declare that they have no competing interests.

\section{Publisher's Note}

Springer Nature remains neutral with regard to jurisdictional claims in published maps and institutional affiliations. 


\section{Author details}

${ }^{1}$ Maternity Teaching Hospital, Kurdistan, Erbil, Iraq. ${ }^{2}$ Kurdistan Board for Medical Specialists, Kurdistan, Erbil, Iraq. ${ }^{3}$ Department of Obstetrics and Gynecology, Hawler Medical University, College of Medicine, Kurdistan region, Erbil, Iraq.

Received: 8 March 2018 Accepted: 22 May 2018

Published online: 29 May 2018

\section{References}

1. Ferlay J, Soerjomataram I, Ervik M, Dikshit R, Eser S, Mathers C, et al. GLOBOCAN 2012 v1.1, Cancer Incidence and Mortality Worldwide: IARC Cancer Base No. 11. Lyon, France. 2014. http://globcan.iarc.fr. Accessed 16 Jan 2015.

2. Management of suspected ovarian masses in premenopausal women (green-top guideline No. 62). Royal College of Obstetrician and Gynecologists. 2011. http://www.rcog.org.uk/globlassets/guidelineslgtg_62pdf. Accessed 24 Feb 2018.

3. Vernooij F, Heintz P, Witteveen E, van der Graaf $Y$. The outcomes of ovarian cancer treatment are better when provided by gynecologic oncologists and in specialized hospitals: a systematic review. Gynecol Oncol. 2007;105:801-12.

4. Sundar S, Reynolds K. Benign and malignant ovarian masses. In: Luesley DM, Baker PN, editors. Obstetrics and gynaecology: an evidence based text for MRCOG. 2nd ed. London: Hodder Arnold; 2010. p. 814-27.

5. Le T, Giede C, Salem S, Lefebvre G, Rosen B, Bentley J, et al. Initial evaluation and referral guidelines for management of pelvic/ovarian masses. J Obstet Gynaecol Can. 2009;31(7):668-80.

6. American College of Obstetricians and Gynecologists' Committee on Practice Bulletins. Practice bulletin No. 174: evaluation and Management of Adnexal Masses. Obstet Gynecol. 2016;128(5):e210-26.

7. Ueland F, DeSimone C, Seamon L, Miller R, Goodrich S, Podzielinski I, et al. Effectiveness of a multivariate index assay in the preoperative assessment of ovarian tumors. Obstet Gynecol. 2011;117:1289-97.

8. Kozak KR, Su F, Whitelegee JP, Faull K, Reddy S, Farias-Eisner R. Characterization of serum biomarkers for detection of early stage ovarian cancer. Proteomics. 2005;5:4589-96.

9. Graham L. ACOG releases guidelines on management of adnexal masses. Am Fam Physician. 2008;77:1320-3.

10. Mutch DG, Prat J. 2014 FIGO staging for ovarian, fallopian tube and peritoneal cancer. Gynecol Oncol. 2014;133(3):401-4.

11. Moorman PG, Calingaert B, Palmieri RT, Iversen ES, Bentley RC, Halabi S, et al. Hormonal risk factors for ovarian cancer in premenopausal and postmenopausal women. Am J Epidemiol. 2008;167:1059-69.

12. Adami HO, Lambe M, Persson I, Ekbom A, Adami HO, Hsieh CC, et al. Parity, age at first childbirth, and risk of ovarian cancer. Lancet. 1994;344:1250-4.

13. Bodelon C, Wentzensen N, Schonfeld SJ, Visvanathan K, Hartge P, Park Y, et al. Hormonal risk factors and invasive epithelial ovarian cancer risk by parity. Br J Cancer. 2013;109:769-76.

14. Tsilidis KK, Allen NE, Key TJ, Dossus L, Lukanova A, Bakken K, et al. Oral contraceptive use and reproductive factors and risk of ovarian cancer in the European prospective investigation into cancer and nutrition. $\mathrm{Br} J$ Cancer. 2011;105:1436-42.

15. Beehler GP, Sekhon M, Baker JA, Teter BE, McCann SE, Rodabaugh KJ, et al. Risk of ovarian cancer associated with BMI varies by menopausal status. J Nutr. 2006;136:2881-6.

16. Collaborative Group on Epidemiological Studies of Ovarian Cancer. Ovarian cancer and body size: individual participant meta-analysis including 25,157 women with ovarian cancer from 47 epidemiological studies. PLoS Med. 2012;9:e1001200.

17. Havrilesky $L$, Gierisch JM, Moorman PG, Coeytaux RR, Urrutia RP, Lowery WJ, et al. Oral contraceptive use for the primary prevention of ovarian cancer. Evid Rep Technol Assess. 2013;212:1-514.

18. Moorman PG, Havrilesky LJ, Gierisch JM, Coeytaux RR, Lowery WJ, Urrutia $R P$, et al. Oral contraceptives and risk of ovarian cancer and breast cancer among high-risk women: a systematic review and meta-analysis. J Clin Oncol. 2013;31:4188-98.

19. Parkin DM. Cancers attributable to exposure to hormones in the UK in 2010. Br J Cancer. 2011;105:S42-8.

20. Collaborative Group on Epidemiological Studies of Ovarian Cancer. Ovarian cancer and oral contraceptives: collaborative reanalysis of data from 45 epidemiological studies including 23,257 women with ovarian cancer and 87,303 controls. Lancet. 2008;371:303-14.

21. Collaborative Group on Epidemiological Studies of Ovarian Cancer. Ovarian cancer and smoking: individual participant meta-analysis including 28,114 women with ovarian cancer from 51 epidemiological studies. Lancet Oncol. 2012;13:936-45.

22. International Agency for Research on Cancer. 2017. List of classifications by cancer sites with sufficient or limited evidence in humans, volumes 1 to 120a. Available from http://monographs.iarc.fr/ENG/classification/Table4.pdf. Accessed 27 Feb 2018.

23. Faber MT, Kjaer SK, Dehlendorff C, Chang-Claude J, Andersen KK, Hogdall E, et al. Cigarette smoking and risk of ovarian cancer: a pooled analysis of 21 case-control studies. Cancer Causes Control. 2013;24:989-1004.

24. Li D, Du C, Zhang Z, Li G, Yu Z, Wang X, et al. Breastfeeding and ovarian cancer risk: a systematic review and meta-analysis of 40 epidemiological studies. Asian Pac J Cancer Prev. 2014;15:4829-37.

25. Maringe C, Walters S, Butler J, Coleman MP, Hacker N, Hanna L, et al. Stage at diagnosis and ovarian cancer survival: evidence from the international cancer benchmarking partnership. Gynecol Oncol. 2012;127:75-82.

26. Khan A, Sultana K. Presenting signs and symptoms of ovarian cancer at a tertiary care hospital. J Pak Med Assoc. 2010;60:260-2.

27. Schutter EM, Keneman P, Sohn C, Kristen P, Crombach G, Westermann R, et al. Diagnostic value of pelvic examination, ultrasound, and serum CA 125 in postmenopausal women with a pelvic mass. An international multicenter study. Cancer. 1994;74:1398-406.

28. Pepin $\mathrm{K}$, Carmen M, Brown A, Dizon DS. CA 125 and epithelial ovarian cancer: role in screening, diagnosis, and surveillance. Am J Hematol Oncol. 2014;10:22-8

29. Ware Miller R, Smith A, DeSimone CP, Seamon L, Goodrich S, Podzielinski I, et al. Performance of the American College of Obstetricians and Gynecologists' ovarian tumor referral guidelines with a multivariate index assay. Obstet Gynecol. 2011;117:1298-306.

30. Longoria TC, Ueland FR, Zhang Z, Chan DW, Smith A, Fung ET, et al. Clinical performance of a multivariate index assay for detecting early-stage ovarian cancer. Am J Obstet Gynecol. 2014;210:78.e1-9.

31. Bristow RE, Smith A, Zhang Z, Chan DW, Crutcher G, Fung ET, et al. Ovarian malignancy risk stratification of the adnexal mass using a multivariate index assay. Gynecol Oncol. 2013;128:252-9.

\section{Ready to submit your research? Choose BMC and benefit from:}

- fast, convenient online submission

- thorough peer review by experienced researchers in your field

- rapid publication on acceptance

- support for research data, including large and complex data types

- gold Open Access which fosters wider collaboration and increased citations

- maximum visibility for your research: over $100 \mathrm{M}$ website views per year

At BMC, research is always in progress.

Learn more biomedcentral.com/submissions 